\title{
EMPRESA JÚNIOR: ESPAÇO PARA CONSTRUÇÃO DE COMPETÊNCIAS
}

\author{
JUNIOR ENTERPRISE: SPACE FOR \\ BUILDING UP COMPETENCIES
}

Recebido em: 24/03/2014 • Aprovado em: 05/06/2014

Avaliado pelo sistema double blind review Editora Científica: Manolita Correia Lima

\section{VALDIRMACHADO VALADÃO JÚNIOR valdirjr@ufu.br RAFAELA CAMPOS DE ALMEIDA CINTIA RODRIGUES DE OLIVEIRA MEDEIROS UNIVERSIDADE FEDERAL DE UBERLÂNDIA}

\section{RESUMO}

No mesmo compasso em que transformações ocorrem na organização do trabalho, estudantes e educadores buscam, além daquelas obtidas dentro da sala de aula, experiências que possam facilitar a aprendizagem. Uma dessas experiências é a participação na Empresa Júnior, um conceito que surgiu com a promessa de ser um laboratório para os estudantes universitários. É nesse contexto que estabelecemos para esta pesquisa o objetivo de identificar e analisar competências desenvolvidas pelos egressos de uma Empresa Júnior sediada em uma instituição federal em Minas Gerais, bem como verificar se as competências constituídas por esses egressos contribuíram para o desenvolvimento de sua carreira profissional. Nossa abordagem é de natureza qualitativa e utilizamos o estudo de caso como estratégia de pesquisa. Para coleta dos dados, entrevistamos egressos de uma empresa júnior do curso de Administração de uma instituição federal, realizamos observação direta nessa empresa júnior e analisamos documentos. Utilizamos a técnica de análise de conteúdo para análise de todo o material coletado. Os resultados apontam que a empresa júnior analisada constitui-se de um espaço para construção de competências, bem como contribui para o desenvolvimento da carreira profissional de seus egressos.

Palavras-chave: competência; empresa júnior; desenvolvimento profissional.

\section{ABSTRACT}

At the same time that changes are happening in the organization of work, students and educators are seeking other experiences that can facilitate learning beyond those obtained in the classroom. One such experience is participation in Junior Enterprise, a concept intended to be a laboratory for students. Within this context, the aim of the research is to identify and analyze the competencies developed by ex-members of a Junior Enterprise program from a University in Minas Gerais, and to verify if these competencies contributed to the development of their professional careers. The paper used a qualitative, case study approach with data collection comprising interviews, direct observation of the Junior Enterprise and document analysis. Content analysis was then performed on all the resulting data. The results indicate the Junior Enterprise in question provides a space for building up competencies and contributes to the career development of its members.

Keywords: competencies; junior enterprise; career development. 


\section{INTRODUÇÃO}

A crise estrutural do sistema capitalista promoveu transformações no ambiente empresarial que desencadearam reestruturações no processo produtivo, na forma de organização do trabalho e no saber do trabalhador (DELUIZ, 2003). As organizações que se encontravam atreladas aos modelos produtivos taylorista/fordista introduziram o padrão de acumulação de capital flexível para lidarem com o novo ambiente econômico e, como consequência, o mundo do trabalho sofreu impactos significativos, e um novo perfil de trabalhador passou a ser requisitado (BAUDOUIN, 2004; RUÉ; ALMEIDA; ARANTES, 2009; NUNES, 20II).

Para acompanhar essas demandas, na década de 1980, os países que ocupavam uma posição periférica passaram a enfrentar o desafio de ampliar as ações voltadas à qualificação e à formação de competência de seus formandos. Dessa forma, algumas inovações foram requeridas da área educacional (NUNES, 20II) e, a partir dos anos I990, as Instituições de Ensino Superior (IEs) brasileiras começaram a promover mudanças nos projetos pedagógicos de seus cursos. Com a Lei de Diretrizes e Bases da Educação Nacional - LDB (Lei n 9.394 de 1996), algumas medidas foram estabelecidas para orientar os cursos de graduação no país e garantir a formação mínima de competências (BRASIL, 1997).

Nesse contexto, após os projetos de extensão, emergiu no Brasil o conceito de Empresa Júnior (EJ), uma associação sem fins econômicos, constituída e gerida, exclusivamente, por estudantes que cursam o ensino superior (BRASIL JÚNIOR, 20II), com o intuito de promover novas competências além daquelas adquiridas dentro de sala de aula e, também, aproximá-los do mercado de trabalho (мAтоs, 1997).

A partir dos anos 1990, surgiram várias federações representando o Movimento da Empresa Júnior, o que alavancou o número dessas organizações nas universidades (мaTOs, 1997) brasileiras. O reflexo disso é que, atualmente, o Brasil é considerado o país com o maior número de EJS (FEJEMG, 2007) com, aproximadamente, I.I20 associações e 27.800 empresários juniores (BRASIL JÚNIOR, 20IO). 
A constatação da necessidade de formação de competências em graduandos e o crescimento acentuado no número de ejs no país estimulam reflexões sobre como essas associações vêm se configurando junto à dinâmica das Instituições de Ensino Superior brasileiras e como essas têm contribuído para a formação profissional de seus integrantes.

Assim, a pesquisa aqui proposta pretende identificar e analisar competências desenvolvidas pelos egressos de uma Empresa Júnior estabelecida em uma instituição federal em Minas Gerais, bem como verificar se as competências constituídas por esses contribuíram para o desenvolvimento de sua carreira profissional. Utilizamos o estudo de caso como estratégia de pesquisa e coletamos os dados na ApoIO consultoria, empresa júnior do curso de Administração de uma instituição federal em Minas Gerais.

O trabalho está estruturado em seis seções, contando com esta introdução. Na segunda e terceira seções, apresentamos o aporte teórico que sustenta a análise de dados; na quarta seção, descrevemos os aspectos metodológicos da pesquisa; na quinta seção, apresentamos os resultados; na sexta seção, encerra-se o artigo com as considerações finais da pesquisa.

\section{CONCEITO DE COMPETENNCIA}

A discussão acerca do conceito de competência não é algo recente. $\mathrm{Na}$ década de 1970, McClelland (1973) iniciou o debate sobre competência, afirmando que as competências, ao invés da inteligência, podem predizer o comportamento e desempenho do indivíduo no trabalho.

É nesse referencial que diversos autores americanos (BOYATZIS, I982; PARRY, I996; MCLAGAN, I997; MIRABILE, 1997) se baseiam. O foco desses trabalhos está nas competências, compreendidas por eles como um conjunto de qualificações (conhecimentos, habilidades e atitudes) que um indivíduo detém e que o possibilita alcançar um desempenho superior em uma situação de trabalho.

Contrariando essa ideia, principalmente, após as mudanças significativas que ocorreram no mundo do trabalho, nos anos de r980 e 1990 (a instabilidade, a descontinuidade e a horizontalidade), os franceses Le Boterf (2003) e 
Zarifian (2008) propuseram outro conceito de competência. Para eles, o trabalho deixou de ser um conjunto de tarefas associadas ao cargo e passou a englobar a capacidade de o indivíduo saber mobilizar os recursos em situações profissionais cada vez mais complexas, imprevistas e mutáveis.

Desaulniers (1997) enfatiza que a competência pode ser construída pelos saberes advindos da qualificação, porém, na mesma perspectiva de Le Boterf (2003), isso não significa que esses dois conceitos sejam equivalentes entre si. No modelo de competências, não basta apenas a posse dos saberes disciplinares escolares ou técnico-profissionais (DELUIZ, 2003).

No campo da administração, Dutra (2004) afirma que as competências individuais devem ser consistentes com as competências essenciais da organização, pois as entregas exigidas das pessoas estão diretamente relacionadas com o objetivo da mesma. Dessa forma, o conceito de competência passou a estar também associado com a agregação de valor, pelo indivíduo, ao meio no qual esse se encontra, ou seja, ao que o indivíduo consegue produzir e entregar às organizações (FLEURY; FLEURY, 200I; DUTRA, 2004).

Sandberg (2000), de forma similar aos autores brasileiros (DESAULNIERS, I997; FleURY; FLeURY, 200I; DELUiz, 2003; DUtra, 2004), afirma que a competência não é, essencialmente, uma lista de conhecimentos, habilidades e atitudes que o indivíduo detém. Esse autor afirma que esses elementos dependem do contexto, e a aquisição dos mesmos ocorre por meio da experiência dos indivíduos no trabalho.

Nessa mesma perspectiva, Cheetham e Chiver (1996; 1998) reconhecem a importância do contexto de trabalho e ambiente de trabalho no processo de construção de competências. Esses autores propuseram um modelo de competências em cujo núcleo existem quatro componentes-chave de competência profissional: (I) Competências funcionais, que são as capacidades de executar uma série de tarefas básicas do trabalho; (2) Competências pessoais ou comportamentais, que são as capacidades de adotar comportamentos adequados e observáveis; (3) Competências cognitivas/ intelectuais, que são definidas como a posse adequada de conhecimentos e à habilidade de colocá-los em prática; e (4) Competências 
éticas/ valores, que são os valores pessoais e profissionais considerados adequados e a capacidade de tomar decisões com base nos mesmos.

Cheetham e Chiver (1996; 1998) apontam que há inter-relações entre as competências citadas anteriormente, formando essas uma série de metacompetências (comunicação, criatividade, solução de problemas e aprendizagem) e transcompetências (autodesenvolvimento, agilidade mental, análise e reflexão) que interagem entre si e produzem uma série de resultados suscetíveis de serem observados/percebidos por si (autopercepção) e pelos outros indivíduos (feedback).

Com base no modelo desses autores, Paiva e Melo (2008) propõem outro conceito de competência profissional, acrescentando aos estudos de Cheetam e Chiver (1996) a competência política, com o propósito de "considerar as relações de poder inerentes a qualquer estrutura organizacional e, daí, as razões e formas de atuação do profissional na teia política intra e interorganizacional” (PAIVA; MELO, 2008, p. 349).

O fato é que, nas últimas décadas, o conceito de competência tem sido abordado em diferentes perspectivas. Observa-se que o mesmo se amplia à medida que novos estudos têm sido realizados. Assim, esse conceito passou a estar relacionado com a mobilização de um conjunto de saberes de naturezas diferenciadas (que formam as competências cognitivas/ intelectuais, funcionais, comportamentais, éticas e políticas) por parte do indivíduo na sua ação produtiva (PAIVA; MELO, 2008),

$\mathrm{Na}$ área acadêmica, como uma tentativa de se adequar à realidade da construção de competências, os projetos de ensino têm incorporado tal conceito. A seguir, será apresentado como esse processo vem ocorrendo no contexto das IES brasileiras, ao longo das últimas décadas.

\section{A INSERÇÃO DO CONCEITO DE COMPETÊNCIAS NO ENSINO SUPERIOR - IFS NO BRASIL}

Nos anos 1990, algumas IEs passaram por reformas sob a orientação e suporte financeiro de organismos internacionais, como parte de um conjunto de outras mudanças estruturais que estavam sendo realizadas no país, visando a superar a estagnação/crise econômica nos anos 1980 e a necessidade de 
articular e subordinar a produção educacional às exigências do mercado (DELUIZ, 2003).

Em 1995, o sistema educacional brasileiro sofreu algumas mudanças, dentre elas, a publicação da Lei 9.I3I (de 24/II/95), que modificou a Lei 4.024 (de 20/12/196I), fixando as Diretrizes e Bases da Educação Nacional (BRASIL, 2002). A Lei 4.024 atribuía ao Conselho Federal de Educação - CFE a competência para estabelecer o currículo mínimo dos cursos de ensino superior (BRASIL, 1997), um sistema que, conforme Ribeiro e Sacramento (2009) têm similaridades com os princípios taylorista.

Com a publicação da nova lei, foram elaboradas as Diretrizes Curriculares Nacionais (DCN) para orientar os cursos de graduação, com o principal objetivo de promover a flexibilização curricular. Desse modo, as DCNs passaram a firmar algumas orientações básicas (comuns aos cursos de graduação) e específicas, por curso (BRASIL, 2002).

Nas Diretrizes Específicas do curso de Administração, encontram-se a definição do perfil desejado do formando e as competências que devem ser formadas pelos estudantes: (I) reconhecer problemas, equacionar soluções, atuar preventivamente; (2) desenvolver a capacidade de expressão e comunicação; (3) refletir e atuar de forma crítica sobre a esfera de produção; (4) desenvolver raciocínio lógico, crítico e analítico; (5) ter iniciativa, criatividade, determinação, vontade política e administrativa, vontade de aprender, abertura às mudanças e consciência da qualidade e das implicações éticas do seu exercício profissional; (6) capacidade de transferir conhecimentos da vida e da experiência em situações de trabalho; (7) capacidade de desenvolver projetos; (8) realizar consultorias (BRASIL, 2005).

Nunes (2010) observa que o ensino baseado na formação de competências impõe o desafio de superar o modelo da simples transmissão de conhecimentos e assumir a construção de competências. Esses aspectos ajudam a romper com a ideia tradicional de ensino baseado em conhecimentos disciplinares isolados/ descontextualizados e se canalizaram para um processo de aprendizagem que contempla atividades de natureza transversal e interdisciplinar. Como resultado, tem-se a formação de novos saberes e competências que aproximam os graduandos da realidade da vida profissional (NUNES, 20II). 
O estreitamento das relações com o mercado de trabalho também é observada nas atividades de extensão (ações encorajadas pelas Diretrizes Curriculares Nacionais, por meio dos princípios seis e sete desse projeto). Essas buscam possibilitar a aquisição de outros conhecimentos, habilidades e competências, além daqueles obtidos dentro de sala de aula (BRASIL, 2002). EJ é uma dessas táticas utilizada pelas IES que permite ao aluno obter experiências que aproximam os aspectos teóricos do curso de graduação às ações do profissional em seu contexto real de trabalho. Na seção seguinte, apresentamos as discussões mais aprofundadas sobre essa atividade de extensão.

\section{EMPRESA JÚNIOR: POSSIBILIDADES E LIMITAÇÕES PARA A CONSTRUÇÃO DE COMPETÊNCIAS}

O conceito de Empresa Júnior surgiu em Paris, no ano de 1967, na L'Ecole Supérieure des Sciences Economiques et Commerciales. No Brasil, esse conceito chegou em 1988, por meio da Câmara de Comércio Franco-Brasileira.

A EJ é uma organização formada e gerida por graduandos do ensino superior que presta serviços (projetos) de consultoria à sociedade, na sua área de atuação, sob a orientação dos professores (BRASIL JÚNIOR, 2OII). O espaço de aprendizagem dessas associações se configura por meio da administração das mesmas pelos alunos e também na realização de projetos de prestação serviços de consultoria para micro e pequenas empresas, promovendo a aproximação entre o conhecimento teórico e prático (матоs, I997; PERES; CARVALHO; HASHIMOTO, 2004; TOLFO; SCHMITZ, 2005; LOPES et al., 2007; MASSENSINI ET AL., 2008; PICCHIAI, 2008; LAUTENSCHLAGER, 2009; BRUM; BARBOSA, 2009; FERREIRA-DA-SILVA; PINTO, 20II; NUNES, 20II).

Matos (1997) afirma que algumas características e experiências francesas foram implantadas nos mesmos moldes, com o intuito de manter os propósitos originais quanto à forma de administração, ao código de ética, ao estatuto, aos conceitos de projetos e a outros aspectos relacionados à organização e estrutura de funcionamento e às relações estabelecidas entre seus membros. Entretanto, outras EJs sofreram algumas transformações para se adaptarem à realidade e condições do país, como: (I) no Brasil, as 
EJs possuem um espaço físico nas dependências das instituições de ensino a que pertencem; (2) os estudantes brasileiros contam com a orientação dos professores na realização de seus projetos; (3) as empresas francesas desenvolvem trabalhos para as empresas de grande porte e, no caso brasileiro, a atenção está voltada para os micro e pequenos empresários.

Conforme esse mesmo autor, essas peculiaridades permitem aos graduandos brasileiros obterem outros aprendizados. Em virtude de os estudantes terem orientação dos docentes para o desenvolvimento de projetos, esses conseguem oferecer uma diversidade maior de serviços, além de não terem que seguir metodologias já prontas.

Na mesma direção, Peres, Carvalho e Hashimoto (2004) enfatizam que a orientação e supervisão dos professores são importantes, uma vez que estimulam no aluno a capacidade de agir, refletir e propor soluções inovadoras, em contraposição à postura esquematizada baseada em experiências prévias.

Outras características dessas organizações no país foram levantadas pela Brasil Júnior, por meio do "Projeto Censo e Identidade" (BRASIL JÚNIOR, 20IO): o tempo médio de permanência dos membros é de I4 meses; realizam em média I3 projetos ao ano; o tempo médio de realização de cada projeto é de três meses; o faturamento anual está entre 3000 e 270000 reais; em média, possuem 58 clientes; $71 \%$ das empresas atendidas são micro empresas e pessoas físicas; os custos fixos mensais giram entre 70 e 3500 reais; $53 \%$ são do gênero feminino e $47 \%$ são do gênero masculino; a idade com maior frequência é a de 20 anos; $99 \%$ são solteiros; e $99 \%$ não têm dependentes diretos.

Além dos perfis supracitados, outros estudos apontaram que a aplicação dos conhecimentos teóricos na prática, desenvolvimento profissional (BRUM; BARBOSA, 2009; LAUTENSCHLAGER, 2009), aquisição de novas habilidades, vontade de empreender (BRUM; BARBOSA, 2009), conhecer a área profissional, desenvolvimento pessoal e curiosidade (LAUTENSCHLAGER, 2009) foram motivos para ingresso de estudantes em ejs.

As contribuições das Empresas Juniores para os acadêmicos são diversas, como o desenvolvimento de habilidades profissionais e pessoais, a construção 
de novos conhecimentos, o desenvolvimento de características de liderança (LOPES et al., 2007), a aproximação do ambiente empresarial (MASSENSINI et al., 2008), o ingresso no mercado de trabalho e o desenvolvimento de características empreendedoras (COSTA; BARROS; MARTINS, 2008; MASSENSINI et al., 2008).

Como possibilidades do espaço de aprendizado dessas organizações, Lautenschlager (2009) identificou: (I) a liberdade de atuação; (2) incentivo à mudança e busca do conhecimento; (3) oportunidade de aprender com 0 erro; (4) aprender novas técnicas; (5) reconhecimento pessoal; (6) atividades similares àquelas quando da atuação no mercado; (7) realização pessoal; (8) contato com outras EJs/ membros; e (9) abordagem de conteúdo que não existe na universidade.

Limitações para que o aprendizado ocorra nas EJs também foram apontadas por Lautenschlager (2009), como: (I) falta de orientação de professores; (2) falta de recursos; e (3) a atividade da EJ não contar pontos no currículo acadêmico.

A despeito das limitações apontadas, as Empresas Juniores têm contribuído para a construção de competências em seus membros. Algumas pesquisas apontaram a constituição das seguintes competências: criatividade, liderança e habilidade de comunicação (LAUTENSCHLAGER, 2009); adaptação, coragem, comprometimento, desinibição, responsabilidade social, cumprir prazos, elaboração de projetos, boa oratória, visão crítica, visão do futuro, conhecimento do MEJ (FERREIRA-DA-SILVA; PINTO, 2OII); ambição profissional, autoconfiança, disposição para treinamento, estabilidade emocional, focar resultados, orientação para a carreira, respeito aos superiores, habilidade intelectual, trabalhar sob pressão, visão do futuro, conhecimento dos princípios científicos (вRUм; BARBOSA, 2009); autonomia, flexibilidade, conhecimento em gestão, da teoria e técnicas da área de atuação (LAUTENSCHLAGER, 2009); espírito empreendedor, capacidade para resolução de problemas (LOPES et al., 2007; вRUM; BARBOSA, 2009); e proatividade (LAUTENSCHLAGER, 2009).

Nesta pesquisa, buscamos identificar e analisar as competências desenvolvidas pelos egressos da Empresa Júnior do curso de Administração 
da Universidade Federal de Uberlândia, Apoio Consultoria, bem como compreender como essas contribuíram para o desenvolvimento da carreira profissional dos ex-empresários juniores, ao longo dos anos. Assim, para a realização da mesma, adotamos um conjunto de procedimentos metodológicos que será apresentado na próxima seção. 


\section{PROCEDIMENTOS DA PESQUISA}

Quanto à forma de abordagem, esta pesquisa classifica-se, dominantemente, como qualitativa, pois temos como preocupação a interpretação das realidades sociais (BAUER; GASKELL; ALLUM, 2002), e de caráter descritivo, conforme a classificação de Santos (2002). A estratégia de pesquisa adotada é o estudo de caso (YIN, 1994).

Adotamos ainda a abordagem quantitativa, restringindo-a a avaliação do perfil dos entrevistados (ex-empresários juniores), para os quais foi aplicado um questionário composto por nove questões, cuja análise limitou-se à estatística descritiva, tendo sido utilizados os recursos da planilha eletrônica (Microsoft Excel) para processamento dos dados.

Para analisar as competências desenvolvidas pelos egressos da Apoio Consultoria, adotou-se como parâmetro o modelo de análise teóricoconceitual sobre competências profissionais, proposto por Paiva e Melo (2008). Esse modelo, além de possibilitar a identificação de competências individuais, também permitiu compreender as inter-relações entre os atores (o Estado, a Instituição de Ensino Superior e a Empresa Júnior) envolvidos, direta ou indiretamente, nesse processo. Entretanto, ressalta-se que, dentre esses atores, este estudo contemplou apenas a EJ.

Desenvolvemos esta pesquisa em quatro fases. A etapa inicial consistiu na busca do referencial teórico com o propósito de aprofundar o conhecimento sobre o problema de pesquisa de forma a permitir a construção dos procedimentos de coleta dos dados. Posteriormente, por meio da observação direta, pesquisa documental e entrevista semiestruturada com membros efetivos da Apoio Consultoria, no início de 2orI, buscamos desenvolver uma compreensão preliminar da área de estudo, ou seja, como essa se configura no ambiente e contexto de trabalho da Apoio Consultoria.

As Diretrizes Curriculares Nacionais do curso de Administração, o estatuto da Apoio Consultoria e o portfólio de projetos foram os documentos analisados. A observação direta ocorreu no mês de fevereiro, quando dedicamos 90 horas no ambiente investigado, compreendidas no período de 60 dias, com o objetivo de acompanhar a dinâmica da Apoio Consultoria. A 
observação direta teve como foco as atividades realizadas pelos empresários juniores, visando a estabelecer uma maior aproximação com o campo e com os sujeitos, conhecer as situações cotidianas do trabalho e identificar as competências requeridas. O registro das observações foi realizado em um diário de campo. Ainda, realizamos entrevistas com 15 dos 19 membros efetivos dessa associação. As informações e evidências coletadas nessa segunda fase foram fundamentais para a construção das questões (tópico guia) que nortearam as entrevistas com ex-integrantes da Apoio Consultoria.

A terceira etapa concentrou-se na realização de entrevistas com os exempresários juniores que participaram dessa associação, entre o período de 1994 (seu surgimento) a 20I0. Nessa fase, optamos pela entrevista episódica, que busca analisar o conhecimento do entrevistado sobre um tema específico (FLICK, 2002). Realizamos 32 entrevistas entre os dias 25 de setembro a 8 de novembro. Todas as entrevistas foram gravadas em áudio, para posterior transcrição e análise de conteúdos, tendo sido geradas 383 páginas de corpus de texto.

Os entrevistados foram distribuídos em categorias: (I) egressos da Apoio até dois anos; (2) de dois a cinco anos; (3) de cinco a dez anos; e (4) a partir de dez anos. Para essa distribuição, consideramos o trabalho de Melo et al. (2010). Essa categorização se justifica pelo fato de as pessoas tenderem a serem mais detalhistas em relação às vivências mais recentes, pois a memória é seletiva e nem tudo consegue ficar registrado (POLLAK, 1992).

A seleção dos entrevistados foi realizada pela "amostragem por bola de neve". Essa técnica de seleção ocorre após a escolha de um grupo inicial de entrevistados de forma aleatória e, posteriormente, os mesmos indicam outros elementos que pertencem à população-alvo de interesse do estudo (MALHOTRA, 200I). Já o critério utilizado para suspensão das entrevistas se deu pela técnica de saturação. Por meio dessa técnica, o pesquisador decide suspender a inclusão de novos membros na amostra, pois o estudo atingiu uma redundância/ repetição dos dados coletados (GASKELL, 2002; FONTANELLA; RICAS; TURATO, 2008).

$\mathrm{Na}$ quarta fase, análise dos dados coletados, utilizamos a técnica de análise de conteúdo que, de acordo com Bauer (2002, p.I9I), "é uma técnica 
para produzir inferências de um texto focal para seu contexto social de maneira objetivada". Ainda, estabelecemos as categorias a priori, com base no esquema teórico de Paiva e Melo (2008): metacompetências e transcompetências; competências cognitivas; funcionais; comportamentais; éticas e políticas. 


\section{APRESENTAÇÃO E ANÁLISE DOS RESULTADOS}

A Apoio Consultoria é a Empresa Júnior do curso de graduação em Administração da Universidade Federal de Uberlândia (UFU). Essa associação foi fundada e registrada em 1994, sob a filosofia de complementar a formação acadêmica, preparar os alunos do curso de Administração para o mercado de trabalho e oferecer serviços de consultoria à sociedade (APOIO CONSULTORIA, 20IO).

Ao longo de dezesseis anos de sua atividade, desde a abertura, em 1994, até o final de 2010, quando esta pesquisa foi concluída, essa Empresa Júnior teve 186 empresários juniores. Com base nas entrevistas, realizadas com 32 ex-integrantes da Apoio, pôde ser identificado um conjunto de competências: metacompetências e transcompetências; competências cognitivas; funcionais; comportamentais; éticas e políticas.

Durante a realização das entrevistas, fizemos perguntas aos exempresários juniores da Apoio Consultoria sobre as atividades realizadas pelos mesmos, tanto nos projetos internos (gestão da associação) quanto aos projetos externos (consultoria) prestados à sociedade, com o objetivo de resgatar as vivências dos mesmos no espaço de aprendizado da EJ da FAGEN/ UFU. Com base nesses relatos, indagamos aos egressos sobre as competências que acreditavam terem desenvolvido por meio das experiências na Apoio Consultoria e como a construção dessas competências contribuiu para sua carreira profissional, ao longo desses anos.

Observamos, pelas entrevistas, que os ex-empresários juniores, com mais de cinco anos, se comparados como os pesquisados das categorias I e 2, egressos até cinco anos, tiveram mais dificuldades em relatar as atividades por eles desempenhadas na Apoio Consultoria. Eles recordavam os fatos, aos poucos. Já os egressos mais recentes respondiam prontamente às questões levantadas na pesquisa. Observamos, ainda, que, nas entrevistas dos pesquisados das categorias 3 e 4 , as falas eram mais "quebradas". Os entrevistados começavam a falar de um assunto e logo já passavam para outro de que haviam se lembrado, o que nos exigiu mais atenção e intervenção. 
Pela análise dos relatos dos entrevistados, verificamos também que as experiências e as competências desenvolvidas por membros das quatro categorias foram similares. Essas competências podem ser observadas, resumidamente, na Tabela I.

Destaca-se, na metacompetência, a habilidade de comunicação e, na competência funcional, a habilidade de liderança, cuja constituição foi indicada por mais da metade dos egressos entrevistados, $56 \%$ e $53 \%$, respectivamente. A habilidade de comunicação e de liderança também foram competências identificadas em diversos estudos (LOPES et al., 2007; BRUM; BARBOSA, 2009; LAUTENSCHLAGER, 2009) Como constituída por empresários juniores. Dos 32 egressos entrevistados, $75 \%$ apontaram que participaram de cargos formais de liderança. A forma de organização das EJs, como o estabelecimento de algumas hierarquias (diretoria e presidência), incentiva e colabora para a consolidação de uma postura de liderança entre os membros que assumem tais posições (LOPEs et al., 2007).

Ainda em relação às competências funcionais, excetuando-se a habilidade de liderança, a capacidade de organização e as habilidades de realizar planejamento e de atendimento/ negociação foram as mais abordadas pelos egressos como constituídas na EJ da FAGEN/ UFU, com 28\%, 22\% e $38 \%$, respectivamente.

Dentre as competências funcionais abordadas na Tabela I, além da habilidade de liderança, duas outras competências também foram levantadas em outras pesquisas, como a habilidade de organização (LOPEs et al., 2007) e habilidade empreendedora/espírito empreendedor (LOPES et al., 2207; BRUM; BARBOSA, 2009).

Nas competências cognitivas, destacam-se a capacidade de mobilizar e transpor conhecimento, que foi abordada por $50 \%$ dos pesquisados, os conhecimentos técnicos em Administração e em consultoria, com $47 \%$ e $44 \%$, respectivamente. Um dos objetivos das empresas juniores é o de proporcionar ao estudante a possibilidade de aplicação prática de conhecimentos teóricos (BRASIL JÚNIOR, 20II). Zarifian (2008, p.72) enfatiza que a competência é um entendimento prático de situações, que se baseia na sabedoria de mobilizar um conjunto de conhecimentos adquiridos 
em uma determinada situação. Na mesma perspectiva, Fleury e Fleury (200I) apontam que o conceito de competência implica em saber mobilizar, integrar, transferir conhecimentos, recursos e habilidades em um contexto.

Observa-se, também, que apenas dois egressos, entre 32 entrevistados, apontaram a constituição do conhecimento sobre a realidade das micro e pequenas empresas. Um número insignificante quando se leva em consideração que esse é o público-alvo que prevalece nos projetos realizados pelas EJs brasileiras (MATOS, I997; FERREIRA-DA-SILVA; PINTO, 2OII; BRASIL JÚNIOR, 20IO).

Tabela I Competências constituídas pelos egressos da Apoio Consultoria

\begin{tabular}{|c|c|c|}
\hline Metacompetências e Transcompetências & F.Absoluta & F. Relativa \\
\hline Habilidades em comunicação & 18 & $56 \%$ \\
\hline Criatividade/ inovação & 4 & $13 \%$ \\
\hline Capacidade de resolução de problemas & 2 & $6 \%$ \\
\hline Autodesenvolvimento & 4 & $13 \%$ \\
\hline Agilidade & 1 & $3 \%$ \\
\hline Visão crítica-analítica & 6 & $19 \%$ \\
\hline Reflexão (autoconhecimento) & 3 & $9 \%$ \\
\hline \multicolumn{3}{|l|}{ Competências Cognitivas } \\
\hline Conhecimentos técnicos em Administração & 15 & $47 \%$ \\
\hline Conhecimentos técnicos em consultoria & 14 & $44 \%$ \\
\hline Conhecimentos técnicos em informática & 6 & $19 \%$ \\
\hline $\begin{array}{l}\text { Conhecimento do mercado/ do ambiente de micro e pequenas } \\
\text { empresas }\end{array}$ & 2 & $6 \%$ \\
\hline Capacidade de transpor e mobilizar os conhecimentos & 16 & $50 \%$ \\
\hline \multicolumn{3}{|l|}{ Competências Funcionais } \\
\hline Capacidade para empreender & 4 & $13 \%$ \\
\hline Habilidade de liderança & 17 & $53 \%$ \\
\hline Capacidade de conduzir reuniões & 1 & $3 \%$ \\
\hline Capacidade de gestão de conflitos & 5 & $16 \%$ \\
\hline Capacidade de tomar decisões & 4 & $13 \%$ \\
\hline Habilidade de administração de tempo & 2 & $6 \%$ \\
\hline Capacidade de organização & 9 & $28 \%$ \\
\hline Habilidade de realizar planejamento & 7 & $22 \%$ \\
\hline
\end{tabular}




\begin{tabular}{|c|c|c|}
\hline Metacompetências e Transcompetências & F.Absoluta & F. Relativa \\
\hline Habilidade de atendimento e negociação & 12 & $38 \%$ \\
\hline Capacidade de estabelecer prioridades & 1 & $3 \%$ \\
\hline Capacidade de lidar com imprevistos & 2 & $6 \%$ \\
\hline \multicolumn{3}{|l|}{ Competências Comportamentais } \\
\hline Capacidade de trabalhar em equipe & 14 & $44 \%$ \\
\hline Relacionamento interpessoal & 14 & $44 \%$ \\
\hline Coragem & 2 & $6 \%$ \\
\hline Sinceridade & 1 & $3 \%$ \\
\hline Senso de cooperação & 1 & $3 \%$ \\
\hline Comprometimento & 3 & $9 \%$ \\
\hline Responsabilidade & 9 & $28 \%$ \\
\hline Foco em resultado & 8 & $25 \%$ \\
\hline Disciplina & 2 & $6 \%$ \\
\hline Proatividade/ iniciativa & 13 & $41 \%$ \\
\hline Habilidade de escutar & 2 & $6 \%$ \\
\hline Paciência & 6 & $19 \%$ \\
\hline Pontualidade & 1 & $3 \%$ \\
\hline Controle emocional (ansiedade) & 1 & $3 \%$ \\
\hline Flexibilidade & 4 & $13 \%$ \\
\hline Autoconfiança/ autoestima & 6 & $19 \%$ \\
\hline Determinação & 4 & $13 \%$ \\
\hline \multicolumn{3}{|l|}{ Competências Éticas } \\
\hline Atitude de respeitar as hierarquias & 2 & $6 \%$ \\
\hline Senso de responsabilidade com os recém-chegados & 1 & $3 \%$ \\
\hline Reconhecimento dos limites das próprias competências & 4 & $13 \%$ \\
\hline Senso de responsabilidade com os clientes & 1 & $3 \%$ \\
\hline \multicolumn{3}{|l|}{ Competências Políticas } \\
\hline Capacidade de se reconhecer como Administrador & 13 & $41 \%$ \\
\hline
\end{tabular}

Fonte: Elaborado pelos autores com base nas respostas dos egressos entrevistados.

Nota: a frequência relativa (F. Relativa.) foi estabelecida em relação ao número total de egressos entrevistados (32)

Outro ponto interessante apontado nesta pesquisa diz respeito às competências cognitivas. Verificamos que o aprendizado de conhecimentos intelectuais não se restringe às salas de aulas, visto que o espaço de trabalho 
da Empresa Júnior também colabora nesse processo. O fato que pode justificar esses números é o ingresso dos alunos na Apoio Consultoria nos primeiros anos de curso. Dentre os pesquisados, 59\% afirmaram ter ingressado na Apoio Consultoria entre o primeiro e segundo ano do curso de Administração, período em que algumas matérias importantes para a realização dos projetos ainda não foram ministradas em sala de aula, como marketing, recursos humanos e finanças. Dessa forma, os estudantes buscam esses conhecimentos antes mesmo de serem abordados no ambiente acadêmico.

Já sobre as competências comportamentais, a capacidade de trabalhar em equipe, o relacionamento pessoal e a proatividade/iniciativa se destacaram, representando, em termos percentuais, $44 \%, 44 \%$, $4 \mathrm{I} \%$, respectivamente. O trabalho em projetos torna coletiva a situação de trabalho, permitindo a mobilização de vários indivíduos em torno de um contexto complexo, que excede a competência de um único indivíduo (ZARIFIAN, 2008).

Como ressaltam alguns autores, a competência se configura na capacidade de crítica e de autonomia (DESAUlNiERs, I997; LE BOTERF, 2003; ZARIFIAN, 2008), no espírito de iniciativa com audácia, na responsabilidade, na flexibilidade face à mudança e ao inusitado, e em uma visão empreendedora (DESAULNIERS, 1997).

Em relação às competências éticas, essas apresentaram baixa incidência. $O$ elemento com maior número de ocorrência nessa categoria foi a capacidade de reconhecimento dos limites das próprias competências, com I3\%. De acordo com as diretrizes específicas do curso de Administração, os egressos desse curso devem ter consciência da qualidade e das implicações éticas do seu exercício profissional (BRASIL, 2005).

Conforme Cheetham e Chivers (1996; 1998), o valor profissional representa a adoção de atitudes adequadas, atenção aos códigos de conduta profissional, autorregulação, sensibilidade ambiental, centralização no cliente, julgamento ético, reconhecimento dos limites das próprias competências, apoio ao desenvolvimento dos recém-chegados na profissão, etc. Isso é explicado por Zarifian (2008), ao afirmar que os valores não são impostos e, sim, emergem em um contexto em que o consenso é facilitado, como ocorre na lógica da competência. 
A competência política também teve baixo nível de incidência. A capacidade de se reconhecer como Administrador foi o único elemento apontado pelos entrevistados. Esse elemento identificado não contempla toda a amplitude de poder presente na perspectiva de Paiva e Melo (2008). A categoria I apresentou maior nível de incidência dessa competência, com 50\%. Embora essa porcentagem seja baixa, de acordo com os dados levantados no questionário de identificação, $72 \%$ dos egressos atuam na sua área de formação, ou seja, em Administração.

Verificamos, ainda, que o fortalecimento da identidade profissional também colaborou no direcionamento da carreira a ser seguida, por alguns pesquisados, dentro da área da Administração. Sandberg (2000) coloca que os atributos utilizados no trabalho são precedidos e baseados na concepção que os profissionais têm a respeito do mesmo. Portanto, é a maneira como os trabalhadores concebem o trabalho que os possibilitam desenvolver, formar e organizar seus conhecimentos e habilidades em distintas competências.

Dentre as seis dimensões de competências identificadas nesta pesquisa, a competência comportamental apresentou maior número de ocorrência, com 91; em seguida, as funcionais, com 64; as cognitivas, com 53; as metacompetências/transcompetências, com 38; as políticas, com I4; e as éticas, com 8.

Quanto à correspondência entre as competências adquiridas pelos egressos e aquelas constantes na proposta de formação de graduandos na Apoio Consultoria, conforme os documentos analisados, observamos que essas estão em consonância. O mesmo ocorre em relação às competências mínimas estabelecidas pelas diretrizes do curso de Administração. Entretanto, outras competências, como a política, foram constituídas no espaço de aprendizado dessa EJ, como será abordado neste artigo.

Sobre as quatro categorias analisadas, verificamos que os pesquisados da Categoria I apontaram a aquisição de 42 competências; da Categoria 2, 32; da Categoria 3, 39; e da Categoria 4, 23. Já a dimensão de competência, que teve maior incidência, em termos quantitativos, nas categorias I, $2 \mathrm{e}$ 3, foram as competências comportamentais, com 32, 2I e 28 ocorrências, respectivamente, e, na categoria 4 , as competências funcionais, com I3. 
Durante as entrevistas, observamos que os egressos da Apoio Consultoria há mais de dez anos, quando questionados sobre as competências que eles haviam constituído no espaço da EJ, ressaltaram aquelas mais marcantes e que, de certa forma, foram as mais mobilizadas no exercício de suas atividades, ao longo desses anos.

No primeiro grupo, os egressos de até dois anos, os pesquisados abordaram as competências que foram constituídas, de forma geral, após as atividades desempenhadas pelos mesmos, o que explica o número de 42 competências apontadas. No segundo e terceiro grupo, alguns entrevistados abordaram as mais marcantes; já outros relataram com mais detalhes suas vivências e aprendizados, o que, também, justifica o número alto de competências levantadas. A despeito dessas diferenças entre as quatro categorias, podemos afirmar, pelos relatos dos entrevistados, que as experiências na Empresa Júnior de Administração da UFU foram relevantes e marcaram tanto a vida profissional quanto pessoal dos egressos.

Para a constituição dessas competências citadas anteriormente, exempresários juniores abordaram algumas possibilidades e limitações do espaço de aprendizado da Apoio Consultoria que contribuíram para a formação das mesmas. Algumas características dessa EJ foram imprescindíveis nesse processo, quais sejam: (I) promove atividades, como os projetos internos e externos; (2) possui estrutura mais descentralizada; (3) possui um ambiente flexível, que dá liberdade e autonomia aos estudantes; (4) tem apoio da Coordenação do curso; (5) tem flexibilidade de horário; (6) funciona sob a orientação de professores; (7) estimula a busca do conhecimento; (8) aproxima o aluno da sociedade e do mercado de trabalho; (9) não exige experiência profissional; (Io) trabalha com o sistema de alocações; (II) acompanha o aprendizado e a construção de competências dos alunos; (I2) estimula o trabalho em equipe; e (I3) tem um ambiente com características de empresas profissionais.

A maioria dessas possibilidades pode ser observada durante o trabalho de campo: promoção de atividades, ambiente flexível de trabalho, apoio da coordenação do curso, orientação dos professores, entre outras. 
No estudo de Lautenschlager (2009), também foram levantados alguns aspectos positivos da EJ, como: (I) a liberdade de atuação; (2) incentivo à busca do conhecimento; (3) oportunidade de aprender com o erro; (4) aprender novas técnicas; (5) reconhecimento pessoal; (6) atividades similares à atuação no mercado; (7) realização pessoal; (8) contato com outras EJs e seus membros; e (9) abordagem de conteúdos não abordados na universidade. Os pontos I, 2 e 6 vão ao encontro dos resultados apontados na presente pesquisa.

$\mathrm{Na}$ observação direta, verificamos que os empresários juniores desenvolvem atividades similares à atuação no mercado, estabelecem contato com outras ejs e seus membros e buscam utilizar novas técnicas de gestão ainda não aprendidas no curso.

De acordo com as entrevistas, podemos afirmar que a maioria das possibilidades foi apontada por pesquisados das categorias i e 2, egressos até cinco anos. A não exigência de experiência profissional para ingressar na EJ, a oferta de atividades, o estímulo à busca do conhecimento, a orientação dos professores, a aproximação com a sociedade e o mercado de trabalho, o ambiente flexível e a estrutura descentralizada dessa associação, o acompanhamento do aprendizado, o trabalho em equipe e o sistema de alocações são condizentes com as necessidades desses pesquisados, bem como a busca de novos conhecimentos e experiências para ingressar no mercado de trabalho.

Outros pontos levantados por ex-empresários juniores da categoria 4, egressos há mais de io anos, como o apoio da coordenação, o trabalho em equipe e o estímulo da busca do conhecimento, podem estar relacionados com a fase introdutória/de desenvolvimento do conceito de EJ e o início das atividades da Apoio Consultoria. Observamos ainda que a aproximação com a sociedade e com o mercado de trabalho já não é mais um valor para os egressos das categorias 3 e 4 , o que pode ser justificado pelo fato de eles já estarem alocados no mercado de trabalho há mais tempo.

Além dessas possibilidades do espaço de aprendizado da Apoio, exempresários juniores elencaram um conjunto de limitações existentes nesse ambiente, como: (I) alta rotatividade; (2) oscilação na demanda de 
projetos externos; (3) limitações de recursos; (4) imaturidade dos alunos; (6) falta de divulgação da EJ. Alguns fatos que corroboram os depoimentos foram identificados na observação direta e registrados no diário de campo: houve períodos em que não havia demanda de projetos externos, e não constatamos o desenvolvimento de atividades da empresa Junior para divulgação de suas atividades.

Alguns desses pontos negativos vão ao encontro das limitações apontadas em outros estudos, como alta rotatividade, falta de experiência e de divulgação, falta de recursos (LOPES et al., 2007; LAUTENSCHLAGER, 2009). As limitações foram mais apontadas por pesquisados das categorias i e 2, e podemos observar que, à medida que o tempo passa, parece haver uma tendência do esquecimento desses aspectos.

As experiências vivenciadas pelos ex-empresários juniores, no ambiente de aprendizado da Apoio Consultoria, possibilitaram a construção de competências que, por sua vez, trouxeram importantes contribuições para o desenvolvimento da carreira profissional dos mesmos. Analisando os depoimentos dos entrevistados, identificamos as seguintes contribuições: (I) aquisição de conhecimentos e habilidades; (2) autoconfiança; (3) autonomia; (4) capacidade de empreender; (5) capacidade de entregar resultados; (6) conhecimentos em consultoria; (7) crescimento pessoal; (8) determinação; (9) disciplina; (Io) escolha da área de atuação; (II) espírito de liderança; (I2) facilidade em aprender; (I3) habilidade de comunicação; (I4) habilidades de gestão; (I5) maturidade; (I6) network; (I7) paciência; (I8) planejamento; (I9) preparação para ingressar no mercado de trabalho; (20) primeira experiência profissional; (2I) proatividade; (22) profissionalismo; (23) relacionamento interpessoal; (24) responsabilidade; (25) saber lidar com situações de crise e conflitos; (26) saber trabalhar em grupo; (27) valorização profissional; (28) visão crítica e analítica; e (29) visão global.

Dentre os pontos abordados pelos ex-membros da EJ de Administração da UFU, o $19^{\circ}$ item, preparação para ingressar no mercado de trabalho, foi mencionado em todas as quatro categorias. Na primeira, esse aspecto foi apontado por todos entrevistados (oito); na segunda, por cinco; na terceira, por quatro; e, por último, na quarta, por um entrevistado. 
A observação direta de reuniões nos permitiu registrar algumas competências: os participantes apresentavam ter conhecimentos e habilidades de negociação, profissionalismo, bom relacionamento interpessoal, responsabilidade, saber trabalhar em grupo e uma visão global das áreas funcionais da administração.

Algumas contribuições levantadas nesta pesquisa vão ao encontro de outros estudos, como o desenvolvimento do espírito de liderança, o desenvolvimento pessoal, a construção de novos conhecimentos (LOPES et al., 2007), ingresso no mercado de trabalho e o desenvolvimento de características empreendedoras (COSTA; BARROS; MARTINS, 2008; MASSENSINI et al., 2008).

Por fim, podemos afirmar, de acordo com as entrevistas, que a Apoio Consultoria é um ambiente de aprendizado que contribuiu tanto no processo de constituição de competências quanto no desenvolvimento da carreira profissional de seus egressos, ao longo desses anos. 


\section{CONSIDERAÇÕES FINAIS}

A questão que orientou este estudo foi delineada ao ser constatada a necessidade de formação de competências em graduandos do curso superior em Administração e o crescimento acentuado do número de Empresas Juniores no país. Compreender como essas organizações vêm se configurando junto à realidade das Instituições de Ensino Superior brasileiras e como essas têm contribuído para a formação profissional de seus integrantes nos levou a estabelecer o objetivo de identificar e analisar as competências desenvolvidas pelos egressos da Empresa Júnior do curso de Administração da Universidade Federal de Uberlândia Ufu, Apoio Consultoria e compreender como essas contribuíram para o desenvolvimento da carreira profissional dos mesmos.

A pesquisa realizada na Apoio Consultoria nos permite afirmar que esse EJ constitui-se um espaço no qual os estudantes têm a oportunidade de mobilizar e contextualizar um conjunto de cHAs, após o enfrentamento de situações (projetos internos e externos) que transcendem os limites de uma disciplina vivenciada em sala de aula. Assim, evidencia-se a possibilidade de manifestações de competências, bem como a incorporação de elementos do saber fazer e do saber ser no processo de formação dos graduandos em Administração da UfU. Além disso, essa EJ tem o objetivo de promover o aprendizado e o desenvolvimento do estudante de acordo com a profissão de formação do mesmo.

Essa afirmação ancora-se nos estudos de diversos autores (DESAULNIERS, I997; FLEURY; FLEURY, 200I; LE BOTERF, 2003; DELUIZ, 2003; ZARIFIAN, 2008) que afirmam que a competência está relacionada com a capacidade/ sabedoria de mobilizar um conjunto de conhecimentos, habilidades e atitudes em determinado contexto de trabalho.

Analisando os depoimentos de ex-consultores, pudemos identificar seis dimensões de competências individuais constituídas pelos egressos da EJ da FAGEN/ UFU: as metacompetências e transcompetências; cognitivas; funcionais; comportamentais; éticas e políticas. Quanto ao número de elementos identificados em cada uma das seis dimensões, houve a 
predominância nas competências técnico-funcionais e comportamentais, o que está em consonância com o objetivo da Apoio Consultoria, que é o de complementar a formação acadêmica e preparar os alunos do curso de Administração para o mercado de trabalho.

De uma forma unânime, ou seja, 100\% dos entrevistados afirmaram que a EJ da FAGEN/ UFU é um espaço com muitas possibilidades e que promove a construção de competências. Esses ex-membros afirmaram que a oportunidade de participar dos projetos dessa associação foi relevante e marcou as suas vidas profissionais.

Sobre as limitações do espaço de aprendizado da Apoio Consultoria, abordadas pelos pesquisados, e as fragilidades identificadas no processo de ensino/aprendizado dessa $\mathrm{EJ}$, por meio desta pesquisa, sugere-se que as mesmas sejam avaliadas pelo colegiado do curso e gestores dessa organização, com o intuito de promover melhorias no processo de formação dos acadêmicos e, assim, alcançar o máximo de aproveitamento do potencial de aprendizado dos mesmos.

Ainda, em relação às fragilidades apontadas (baixa construção de competências éticas e políticas entre ex-empresários juniores da EJ da FAGEN/ UFU), espera-se que essas provoquem reflexões sobre as implicações do não desenvolvimento de tais competências entre graduandos e, também, sobre o papel e as ações efetivas dos diferentes atores sociais (Estado, IES e eJs) no processo de formação desses futuros profissionais e, principalmente, dos cidadãos (sujeitos éticos e políticos) na sociedade.

Retomando o objetivo a que nos propomos alcançar, identificamos e analisamos as competências desenvolvidas pelos egressos da Empresa Júnior do curso de Administração da Universidade Federal de Uberlândia - Ufu, Apoio Consultoria, e buscamos explicações sobre o modo como essas contribuíram para o desenvolvimento da carreira profissional dos participantes, o que se constitui em uma contribuição para os coordenadores de cursos e todos aqueles envolvidos na concepção e desenvolvimento de empresas juniores. Como esta pesquisa surgiu no contexto do Programa de Apoio ao Ensino e à Pesquisa Científica e Tecnológica em Administração (Pró-Administração), bem como da linha "Organização e Mudança" do 
Programa de Pós-Graduação em Administração da Universidade Federal de Uberlândia - Ufu, estima-se que este estudo promova contribuições para o processo de ensino e aprendizado dos estudantes de graduação do curso de Administração da Ufu, por meio de reflexões que poderão emergir com base nos resultados identificados.

Em termos de limitações da pesquisa realizada, algumas devem ser consideradas. A primeira está relacionada à fidedignidade dos fatos relatados pelos egressos da Apoio Consultoria. As considerações dos pesquisadores foram realizadas com base nos depoimentos dos entrevistados. A segunda diz respeito à informalidade dos documentos. Devido à alta rotatividade de estudantes na EJ, observou-se que nem todos os arquivos e processos da EJ apresentam uma organização formal. Uma terceira limitação refere-se à impossibilidade de generalização dos resultados, pois esses se referem às vivências de um grupo específico de sujeitos, não podendo, assim, serem transpostos a outros contextos.

Finalmente, a título de sugestão, apontamos para o desenvolvimento de outros estudos que aprofundem os resultados alcançados nesta pesquisa, uma vez que muitas universidades públicas e privadas possuem Ejs, o que torna interessante conhecer como essas associações estão se desenvolvendo entre os diferentes espaços de ensino/aprendizagem no país. Pensando em uma agenda de pesquisa, sugerimos: (I) a reaplicação desta pesquisa em outras ejs; (2) analisar, comparativamente, resultados de ejs de instituições públicas e privadas, principalmente, quanto às limitações para que a EJ se constitua em espaço de construção de competências; (3) levantar outras competências não citadas nesta pesquisa. 


\section{REFERÊNCIAS}

APOIO CONSULTORIA. Empresa Júnior do curso de Administração da Universidade Federal de Uberlândia (UFU). Portfólio Apoio Consultoria. Uberlândia, 2011.

BAUDOUIN, J. M. A competência e a questão da atividade: rumo a uma nova conceituação didática da formação. In: OLLAGNIER, E.; DOLZ, J. (Org.). O enigma da competência em educação. Porto Alegre: Artmed, 2004. p. 151-171.

BAUER, M. W. Análise de Conteúdo Clássica: uma revisão. In: BAUER, M. W; GASKELL, G. Pesquisa qualitativa com texto, imagem e som: um manual prático. Tradução de Pedrinho A. G. Petrópolis/RJ: Vozes, 2002.

; GASKELL, G.; ALLUM, N. C. Qualidade, Quantidade e Interesses do Conhecimento. In: BAUER, M. W; GASKELL, G. Pesquisa qualitativa com texto, imagem e som: um manual prático. Tradução de Pedrinho A. G. Petrópolis/RJ: Vozes, 2002.

BOYATZIS, R. E. The competent manager. New York: Wiley, 1982.

BRASIL. Ministério da Educação. Conselho Nacional de Educação/ Câmara de Educação Superior. PARECER N ${ }^{\circ}$ CES n ${ }^{\circ} 776 / 97$, aprovado em 03/12/1997. Diretrizes Curriculares Nacionais dos cursos de graduação em Direito, Ciências Econômicas, Administração, Ciências Contábeis, Turismo, Hotelaria, Secretariado Executivo, Música, Dança, Teatro e Design. Brasília, DF, 1997.

Ministério da Educação. Conselho Nacional de Educação/ Câmara de Educação Superior. PARECER CES/ CNE no 0146/2002, aprovado em 03/04/2002. Diretrizes Curriculares Nacionais dos cursos de graduação em Direito, Ciências Econômicas, Administração, Ciências Contábeis, Turismo, Hotelaria, Secretariado Executivo, Música, Dança, Teatro e Design. Brasília, DF, 2002.

Ministério da Educação. Conselho Nacional de Educação/ Câmara de Educação Superior. Parecer CNE/CES no 227/2005, aprovado em 07 de julho de 2005. Diretrizes Curriculares Nacionais do Curso de Graduação em Administração, bacharelado. Brasília, DF, 2005.

BRASIL JÚNIOR. Confederação Brasileira de Empresas Juniores. Relatório Nacional Censo e Identidade 2010. São Paulo, 2010.

Confederação Brasileira de Empresas Juniores. Conceito Nacional de Empresa Júnior. São Paulo, 2011.

BRUM, M. A. C.; BARBOSA, R. R. Comportamento de busca e uso da informação: um estudo com alunos participantes de empresas juniores. Perspectivas em Ciência da Informação, v. 14, n. 2, p. 52-75, 2009.

CHEETHAM, G; CHIVER, G. Towards a holistic model of professional competence. Journal of European Industrial Training, v. 20, n.5, p. 20-30, 1996.

The reflective (and competent) practitioner: a model of professional 
competence which seeks to harmonise the reflective practitioner and competencebased approaches. Journal of European Industrial Training, v. 22, n.7, p. 267-276, 1998. COSTA, A. M.; BARROS, D. F.; MARTINS, P.E.M. Linguagem, relações de poder e o mundo do trabalho: a construção discursiva do conceito de empreendedorismo. Revista de Administração Pública, v. 42, n. 5, p. 995-1918, 2008.

DELUIZ, N. O modelo das competências profissionais no mundo do trabalho e da educação: implicações para o currículo. Boletim Técnico do Senac, v. 27, n. 3, p. 13-25, 2003.

DESAULNIERS, J. Formação, competência e cidadania. Educação e Sociedade. Campinas, n. 60, p. 51-63, 1997.

DUTRA, J. S. Competências: Conceitos e Instrumentos para a Gestão de Pessoas na Empresa Moderna. São Paulo: Atlas, 2004.

FEJEMG. Federação das Empresas Juniores do Estado de Minas Gerais. Manual de Constituição e Administração de Empresas Juniores. 2007. Disponível em: < http:// www.concentro.org.br/portal/attachments/013 Manual de Criacao de Empresas Juniores.pdf $>$ Acesso em: 10/07/2012.

FERREIRA-DA-SILVA, R. C.; PINTO, S. R. DA R. Organização de aprendizagem em uma empresa júnior. Administração: Ensino e Pesquisa, v. 12, n. 1, p. 11-39, 2011.

FLEURY, A.; FLEURY, M. T. L. Construindo o Conceito de Competência. Revista de Administração Contemporânea, Edição Especial, p. 183-196, 2001.

FLICK, U. Entrevista episódica. In: BAUER, M. W; GASKELL, G. Pesquisa qualitativa com texto, imagem e som: um manual prático. Tradução de Pedrinho A. G.

Petrópolis/RJ: Vozes, 2002.

FONTANELLA, B. J. B.; RICAS, J.; TURATO, E. R. Amostragem por saturação em pesquisas qualitativas em saúde: contribuições teóricas. Cad. Saúde Pública, Rio de Janeiro, p. 17-27, 2008.

GASKELL, G. Entrevistas individuais e de grupos. In: BAUER, M. W; GASKELL, G. Pesquisa qualitativa com texto, imagem e som: um manual prático. Tradução de Pedrinho A. G. Petrópolis/RJ: Vozes, 2002.

LAUTENSCHLAGER, F. B. Percepção dos Graduandos sobre o Desenvolvimento de Competências em uma Empresa Júnior de Psicologia. 2009. 110f. Dissertação (Mestrado em Psicologia). Programa de Pós-Graduação em Psicologia da Universidade Federal de Santa Catarina. Florianópolis, 2009.

LE BOTERF, G. Desenvolvendo as Competências dos Profissionais. Porto Alegre: Bookman, 2003.

LOPES, M. C.; LOPES, P. C.; LIMA, Z. A. A. de; DALMAS, J. C. Contribuição da Empresa Júnior de Administração no Brasil. Revista ANGRAD, v. 8, n.1, p. 33-52, 2007. MALHOTRA, N. Pesquisa de Marketing: uma Orientação Aplicada. 3.Ed. Porto Alegre: Bookman, 2001. 
MASSANSINI, A. R.; DO CARMO, D. S., SILVA, C. S.; MARQUES, I. C.. Empresa Júnior da UniEvangélica: uma experiência promissora na consultoria de empresas e formação de acadêmicos de Administração. Revista Administração-Ação, v. 5, n.1, p. 21-33, 2008.

MATOS, F. A Empresa Júnior no Brasil e no Mundo. Rio de Janeiro: Martin Claret, 1997.

McCLELLAND, D. G. Testing for competence rather than for "intelligence". American Psychologist, v. 28, n.1, p. 1-14, 1973.

McLAGAN, P. Competencies: the next generation. Training \& Development, v. 51, n. 5, p. 40-47, 1997.

MELO, M. C. de O. L.; MUYLDER, C. F.; LOPES, A. L. M.; CASSINI, M. R. de O. L.; RABELO, N. G. O Empreendedorismo e o Papel das Incubadoras para as Empresas Graduadas de Base Tecnológica da Região Metropolitana de Belo Horizonte. Revista INGEPRO - Inovação, Gestão e Produção, v. 2, n. 6, p. 50-62, 2010.

MIRABILE, R. J. Everything you wanted to know about competency modeling. Training \& Development, v. 51, n. 8, p. 53-58, 1997.

NUNES, S. C. Ensino em Administração: análise à luz da abordagem das competências. Revista de Ciências da Administração, v.12, n. 28, p.198-223, 2010.

Formar competências: uma realidade no curso de Administração? Revista

Gestão e Planejamento, Salvador, v. 12, n. 2, p. 152-178, 2011.

PAIVA, K. C. M.; MELO, M. C. de O. L. Competências, Gestão de Competências e Profissões: Perspectivas de Pesquisas. Revista de Administração Contemporânea, v. 12, n. 2, p. 339-368, 2008.

PARRY, S. B. The quest for competencies. Training \& Development, v. 33, n.7, p. 48-54, 1996.

PERES, R. S.; CARVALHO, A. M. R.; HASHIMOTO, F. Empresa Júnior: integrando teorias e práticas em Psicologia. Revista Psicologia: Organização e Trabalho, v.4, n.2, p.11-30, 2004.

PICCHIAI, D. Empresa Júnior: um exemplo de pequena empresa. Revista Administração em Diálogo, v. 2, n. 11, p. 35-52, 2008.

POLLAK, M. Memória e Identidade Social. Estudos Históricos, v. 5, n. 10, p. 200-212, 1992.

RIBEIRO, D. A.; SACRAMENTO, A. R. S. Ensino e currículo em Administração: a opção brasileira. Revista Gestão e Planejamento, v. 10, n. 2, p. 193-205, 2009.

RUÉ, J.; ALMEIDA, M. I.; ARANTES, V. A. (Org.). Educação e competências: pontos e contrapontos. São Paulo: Summus, 2009.

SANDBERG, J. Understanding Human Competence at Work: An Interpretative Approach. Academy of Management Journal, v. 43, n. 1, p. 9-25, 2000. 
\& OUTROS

SANTOS, A. R. Metodologia científica: a construção do conhecimento. 5.ed. Rio de Janeiro: DP\&A, 2002.

TOLFO, S.R.; SCHMITZ, S. A formação de consultores em uma empresa júnior. Revista ANGRAD, v. 6, n. 2, p. 25-40, 2005.

ZARIFIAN, P. Objetivo Competência: Por uma nova lógica. São Paulo: Atlas, 2008. YIN, R. K. Case study research: design and methods. 2.ed. Thousands Oaks: Sage Publications, 1994. 


\section{DADOS DOS AUTORES}

VALDIR MACHADO VALADÃO JÚNIOR* valdirjr@ufu.br Doutor em Engenharia de Produção pela UFSC

Instituição de vinculação: Universidade Federal de Uberlândia Uberlândia/MG - Brasil

Áreas de interesse em pesquisa: Estudos Organizacionais e formação de administradores.

*Av. João Naves de Avila, 2121-bloco 1F Santa Monica Uberlândia/MG 38411-196

RAFAELA CAMPOS DE ALMEIDA rafaelaacm@yahoo.com.br Mestre em Administração pela UFU

Instituição de vinculação: Universidade Federal de Uberlândia Uberlândia/MG - Brasil

Áreas de interesse em pesquisa: Competências e formação de administradores.

CINTIA RODRIGUES DE OLIVEIRA MEDEIROS cintia@fagen.ufu.br Doutora em Administração pela FGV/EAESP

Instituição de vinculação: Universidade Federal de Uberlândia

Uberlândia/MG - Brasil

Áreas de interesse em pesquisa: Estudos Organizacionais. 